European Journal of Science and Technology

Special Issue, pp. 74-81, October 2019

Copyright (C) 2019 EJOSAT

Research Article

\title{
Akıllı Ev Sistemleri için Geliştirilen Yapay Sinir Ağı Tabanlı Gezgin Hizmet Robotu
}

\author{
Cevdet Tamer Güven ${ }^{1 *}$, Mehmet Ac1 ${ }^{2}$ \\ ${ }^{1}$ Mersin Üniversitesi, Mühendislik Fakültesi, Bilgisayar Mühendisliği Bölümü, Mersin, Türkiye (ORCID: 0000-0003-4767-3942) \\ ${ }^{2}$ Mersin Üniversitesi, Mühendislik Fakültesi, Bilgisayar Mühendisliği Bölümü, Mersin, Türkiye (ORCID: 0000-0002-7245-8673)
}

(Bu yayın HORA 2019 kongresinde sözlü olarak sunulmuştur.)

(First received 1 August 2019 and in final form 22 October 2019)

(DOI: 10.31590/ejosat.636386)

ATIF/REFERENCE: Güven, C. T. \& Acı, M. (2019). Akıllı Ev Sistemleri için Geliştirilen Yapay Sinir Ağı Tabanlı Gezgin Hizmet Robotu. European Journal of Science and Technology, (Özel Sayı), 74-81.

\section{Öz}

Bu çalışmada akıllı ev sistemlerinde kullanılmak üzere Arduino ve çeşitli sensörlerle çalışan bir robot geliştirilmiştir. Çalışmanın amacı akıllı ev sisteminde herhangi bir arıza ya da elektrik kesintisi olması durumunda robotun devreye girerek ev içerisindeki tüm odaları gezmesi ve odalar içerisindeki acil durumları SMS yoluyla kullanıcılara haber vermesini sağlamaktır. Çalışmada yön bulmak için 2 farklı algoritma kullanılmıştır. Bu algoritmalar duvar takibi algoritması ve Proportional Integral Derivative (PID) algoritmasıdır. Veri kümesi, robot ev içerisinde gezerken sensörlerden alınan veriler ile oluşmaktadır. Verilerin eğitim ve test olarak ayrıştırılmasında 10katlı çapraz doğrulama kullanılmıştır. Veriler, yapay sinir ağlarının Multilayer Perceptron (MLP) algoritması ile robota öğretilmiş ve anormal durumların tespit edilmesi sağlanmıştır. Elde edilen performans değerleri 8. katta MSE için 0.1241, MAE için 0.0826 ve R için 0.9792 olarak hesaplanmıştır. Çalışmada elde edilen sonuçlar, çalışmanın bu tip problemlerde etkin kararlar verebildiğini ve geliştirilebileceğini göstermiştir.

Anahtar Kelimeler: Robotik, Yapay sinir ağları, Çok katmanlı ağlar, Arduino.

\section{Artificial Neural Network Based Mobile Service Robot Developed for Smart Home Systems}

\begin{abstract}
In this study, a robot working with Arduino and various sensors has been developed for use in smart home systems. The aim of the study is to enable the robot to walk through all the rooms in the house in case of any breakdown or power failure in the smart home system and to notify the users of the emergencies in the rooms via SMS. Two different algorithms were used to find directions. These algorithms are the wall tracking algorithm and the Proportional Integral Derivative (PID) algorithm. The data set consists of data from the sensors as the robot travels through the house. 10-fold cross-validation was used to separate the data as training and test. The data were taught to the robot by the Multilayer Perceptron (MLP) algorithm of artificial neural networks and it was provided to detect abnormal conditions. The obtained performance values were calculated as 0.1241 for MSE, 0.0826 for MAE and 0.9792 for R at the fold number 8. The results obtained in this study showed that the study can make effective decisions and be developed for these kinds of problems.
\end{abstract}

Keywords: Robotic, Artificial neural network, Multilayer perceptron, Arduino.

\footnotetext{
* Sorumlu Yazar: Mersin Üniversitesi, Mühendislik Fakültesi, Bilgisayar Mühendisliği Bölümü, Mersin, Türkiye, ORCID: 0000-0003-4767-3942, ctamerguven@gmail.com
} 


\section{Giriş}

Robotlar günümüzde her alanda birçok görevi insanların yerine yapabilmektedirler. Bunun nedeni, insanları oluşabilecek tehlikelerden korumak ve oluşabilecek insan hatalarını en aza indirmektir. Robotlar kullandıkları çalışma alanlarına göre hareketli veya sabit olabilirler. Labirent çözen robotlar, doğru akım ile çalışan motorlar vasıtasıyla hareketli robot sınıfina girerler. Labirent çözen robotlar günümüzde insanları çeşitli tehlikelerden korumak için ya da belirlenmiş bir görevi gerçekleştirebilmek için kullanılmaktadır. Bu tarz robotlar askeri alanlarda, evlerde, fabrikalarda kullanılmaktadır. Askeri alanlarda, insanların giremeyeceği yerlere girip çıkabilir, zorlu koşullar altında istenilen görevleri gerçekleştirebilirler. Fabrikalarda, yangın söndürmek amacıyla bulunduğu yerden yangının olduğu yere gidebilir. Evlerde ise temizlik amacıyla kullanılabilirler. Bu tarz robotlar, üzerlerindeki devre kartı vasıtasıyla yapacağı işe göre programlanabilir.

Çalışmada tasarlanan robotun hareket etmesi için bir karar mekanizmasına ihtiyacı vardır. Bu karar mekanizması robotun üzerindeki devre kartında işlenmektedir. Robotun üzerindeki sensörler vasıtasıyla alınan veriler devre kartı üzerinde matematiksel olarak işlenir ve işlemler sonucunda motora hareket veren komutlar çalışır. En çok kullanılan labirent çözme algoritmaları, duvar takip algoritması, Proportional Integral Derivative (PID) algoritması, Tremux's algoritması ve A* algoritmasıdır. Bu çalışmada yön bulmak için PID ve duvar takip algoritması kullanılmıştır.

PID algoritması, girişin oran-integral-türev değerlerini ve/veya bunların kombinasyonlarını alarak sistemlerin denetlenmesini sağlayan kontrolörler genel haliyle P, PI, PD ve PID olarak kullanılmaktadır. PID kontrolörlerin parametreleri hem deneysel hem de analitik olarak elde edilebilmektedir. Ayrıca tasarım aşamaları fazla işlemler içermemektedir. Bu nedenle endüstriyel uygulamalarda yaygın olarak kullanılmaktadırlar (Vatansever ve Deniz, 2013).

Bir bilgisayar sisteminin insan zekâsına özgü özellikleri olan; görsel algılama, ses tanıma, düşünme, fikir üretme, problem çözme, öğrenme, anlam çıkarma, geçmiş deneyimleri muhafaza etme ve karar verme gibi yüksek bilişsel fonksiyonları veya otonom davranışları sergilemesi yapay zekâ olarak tanımlanabilir (Yıldız ve Yıldırım, 2018). İlk defa 1950'li yıllarda ortaya atılan yapay zekâ terimi zaman içinde oldukça yoğun ilgi görmüş ve 40-50 yıllık bir zaman diliminde hayatın vazgeçilmez parçası olan sistemlerin doğmasına neden olmuştur (Akkaya, 2017). Yapay zekâ altında geliştirilen birçok algoritma bulunmaktadır. Bir makinenin bir problemle karşılaştığ 1 zaman problemi analiz etme, yönelme, çözme ve çözümü öğrenme aşamalarının her biri için ayrı ayrı algoritmalar kullanılabilir (Güllü, 2017).

Yapay Sinir ağları insan beyninin en temel özelliği olan öğrenme fonksiyonunu gerçekleştiren bilgisayar sistemleridir. Öğrenme işlemini örnekler yardımı ile gerçekleştirirler. Bu ağlar birbirine bağlı proses elemanlarından (yapay sinir hücrelerinden) oluşur. Her bağlantının bir ağırlık değeri vardır. Yapay sinir ağının sahip olduğu bilgi bu ağırlık değerlerinde saklı olup ağa yayılmıştır (Öztemel, 2003). Çalışmada yapay sinir ağları'nın (YSA) Multilayer Perceptron (MLP) modeli kullanılmıştır.

MLP, yapay sinir ağlarının geriye yayılım algoritması kullanan uygulamalarında en çok tercih edilen modeldir. MLP'de ă̆ mimarisini tasarlamak en önemli noktadır. Ağ yapısındaki bağlantı eksikliği modelin ağı çözemez hale gelmesine neden olabilir (Lins ve Ludermir, 2005).

Robotun evi gezerken SD kartın içine kaydettiği verileri YSA'nın MLP modeli ile öğrenerek olası tehlike durumlarını tespit etmesi amaçlanmıştır. Aynı zamanda kaydedilen veri kümesine 10 katlı çapraz doğrulama uygulanmıştır. Modelin başarısı 3 kritere göre hesaplanmıştır: MSE (Ortalama Karesel Hata), MAE (Ortalama Mutlak Hata) ve R (Çoklu Kolerasyon Katsayısı).

Çapraz doğrulama, mevcut tüm örnekleri eğitim ve test örnekleri olarak kullanan bir bilgisayar tekniğidir. K-kat çapraz doğrulama tekniğinde, tüm veri kümesi rastgele bir birini dışlayan farklı ve hemen hemen eşit büyüklükteki K kadar alt kümeye ayrılır. Sınıflandırma algoritması K kez eğitilir ve test edilir. Her seferinde kümelerden rastgele birisi test verisi olarak alınır ve geri kalan küme verileri eğitim için kullanılır (Barışçıl, Çetin, Er ve Temurtaş, 2012).

$\mathrm{Bu}$ çalışmada akıllı ev sisteminde olası bir arıza durumunda devreye girecek ve ev hakkında kullanıcılara bilgi verecek Arduino tabanlı yapay sinir ağları kullanan bir gezgin hizmet robotu tasarlanmıştır.

Çalışmada sensörlerden toplanan veri kümesini işleyebilmek için temel işlem birimi olarak Arduino kullanılmıştır. Arduino bir giriş/çıkış (input/output) kartı ve Java tabanlı bir dilin yer aldığ 1 geliştirme ortamından oluşan bir fiziksel programlama platformudur. Arduino tek başına çalışan etkileşimli nesneler geliştirmek için kullanılabileceği gibi bilgisayar üzerinde çalışan yazılımlara da (ör: Adobe Flash) bağlanabilir. Arduino IDE kod editörü ve derleyici olarak görev yapan, aynı zamanda derlenen programı karta yükleme işlemini de yapabilen, her platformda çalışabilen Java programlama dilinde yazılmış bir uygulamadır (Ersoy, Madran ve Gülbahar, 2011).

\section{Materyal ve Metot}

Çalışma, robot ve sensörlerin oluşturduğu donanım kısmı ve geliştirilen yapay zekâ yazılımı olmak üzere 2 kısımdan oluşmaktadır.

\subsection{Donanım}

Robotun tasarımında işlem birimi olarak Arduino Uno kullanılmıştır. Arduino temel olarak, çeşitli sensörler ve elektronik komponentlerle haberleşmemizi sağlamakla birlikte sensör ve komponentlere bazı görevler yaptırabilmeye imkân veren devre kartıdır. 
Robotun ev içerisinde engellere çarpmadan yolunu bulması için 3 adet HCSR04 ultrasonik mesafe sensörü kullanılmıştır. Ultrasonik mesafe sensörü ses dalgaları ile mesafe ölçmeye yarar. Ses dalgaları arduino kartında işlenerek cm, mm vs. cinsinden sonuçlar elde edilir. HC-SR04 ultrasonik mesafe sensörü, bir verici ve alıcıya sahiptir. Fiziksel nesnelerden mesafeyi hesaplamak için sonar kullanır. Yüksek doğrulukla $2 \mathrm{~cm}$ ile $400 \mathrm{~cm}$ arasında mükemmel bir nesne algılama aralığına sahiptir. Ultrasonik sensörler ultrasonik dalgayı ileterek fiziksel nesnenin mesafesini hesaplar ve daha sonra yansıma dalgasını tespit eder (Asadullah ve Ullah, 2017).

Verileri kaydetmek için SD kart modülü kullanılmıştır. Robot otonom olarak ev içerisinde hareket ederken ultrasonik mesafe sensöründen alınan verileri SD kart modülü içerisindeki hafıza kartında bir dosya açarak buraya yazmaktadır. Daha sonra bu verilerle yapay sinir ağı modelleri kullanılarak öğrenme ve tahmin etme işlemi gerçekleştirilecektir. SD kart küçük, iyi ve genel bir depolama bileşenidir. Arduino, SD kartla seri çevre arabirimi (SPI) üzerinden kolayca iletişim kurabilir. SPI, Arduino’nun desteklediği senkron seri haberleşme türlerinden biridir. Arduino Uno'daki 12 nolu dijital pin doğrudan SD kartın 7 nolu pinine, Arduino'nun 10, 11 ve 13 nolu pinleri ise mantık seviyesinde dirençli voltaj bölücü tarafından (3.3V) SD kartın ilgili SCLK, MOSI, MISO ve SS pinlerine bağlanır (Yu ve ark., 2017).

Robot üzerinde ev içerisindeki olası gaz kaçaklarını algılaması için MQ5 gaz sensörü kullanılmaktadır. Aynı zamanda girdiği odanın sıcaklık ve nem değerlerini ölçmesi için DHT11 1sı ve nem sensörü kullanılmıştır. MQ5 gaz sensörü LPG, doğal gaz ve hava gazına karşı yüksek hassasiyete sahiptir. Aynı zamanda alkol ve dumana karşı küçük bir duyarlılığa sahiptir. Hızlı, sağlam ve uzun ömürlü bir sensördür (Kasbe ve ark, 2015). DHT11 hali hazırda kalibre edilmiş bir dijital sinyal çıkışı olan sıcaklık ve nem sensörüdür. Sensör, dirençli bir nem bileşeni olan NTC sıcaklık sensörü içerir. 8 bitlik yükssek performanslı bir bağlantı içeren tek çipli mikrodenetleyici, sensöre mükemmel bir kalite, süper hızlı tepki, sıkışma önleme yeteneği ve uygun maliyet sunar (Zhou ve ark, 2012).

Robotun hareket edebilmesi için 1293d motor sürücü entegre kullanılmıştır. Hazır olarak alınan motor sürücü kartları SD kart modülündeki pinlerle çakıştığı için tercih edilmemiştir. 1293d entegresiyle bir devre tasarlanmış ve bu devreye SD kart modülü eklenmiştir. Bu sayede sorunsuz çalışabilecek bir devre kartı imal edilmiştir. Tasarlanan kart Şekil. 1'de gösterildiği gibidir. L293D motor sürücü entegresi, DTL ve TTL mantığını kabul eden yüksek akım ve voltaj ile çalışan dört kanallı bir sürücüdür. Bu, kanal başına $600 \mathrm{~mA}$ çıkış akımı kabiliyeti sağlar ve ayrıca aşırı sıcaklık korumasına sahiptir. Motorları sürmek ve yüksek akım sağlamak için yarım H köprüsü kullanır (Chauhan ve Semwal, 2013). Robota hareket verebilmek için 2 adet dc motor ve bu motorlara uyumlu 2 adet tekerlek kullanılmıştır.

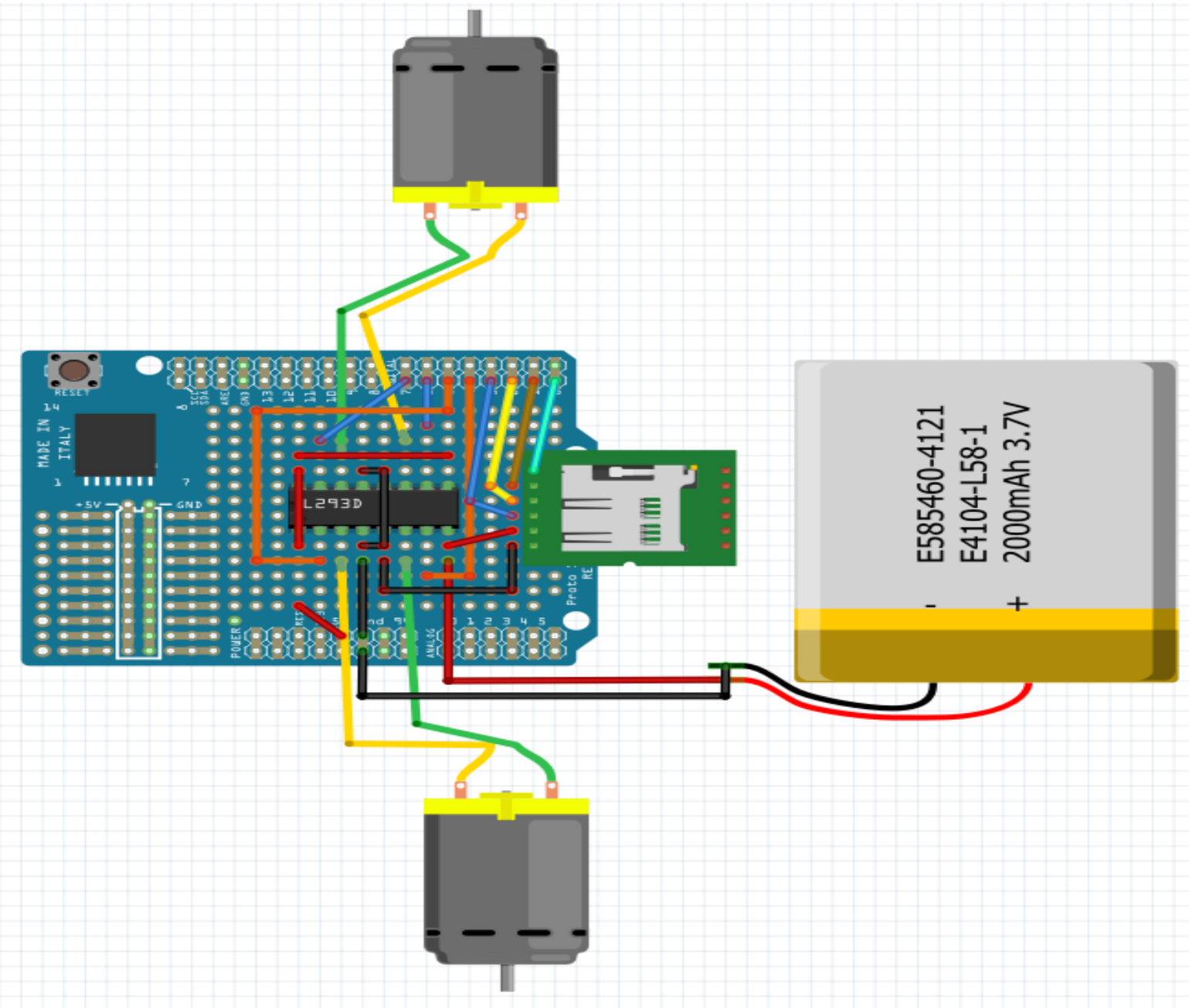

Şekil. 1 DIY motor sürücü devresi ve SD kart modül bağlantısı 
Alev Sensörü, yangın durumunda kullanıcılara bilgi vermektedir. GSM modülü kullanıcı ile robot arasında acil durumlarda ya da kullanıcıların herhangi bir sorgulama yapması durumunda iletişimi sağlamaktadır. GSM modülü, önerilen sistemin kısa metin mesajları gönderip alabilmesini, sesli çağrılar yapabilmesini ve internete bağlanabilmesini sağlar. Bu tür modüller uyumlu olması şartıyla mikrodenetleyici kartlarıyla birlikte kullanılabilirler. GSM modülünün 2 temel bağlantısı, mikrodenetleyicinin seri veri gönderen GSM modülüne bağlanmasına izin veren TX ve RX pinleridir. GSM modülü, bir SIM kart ile çalışır. SIM kart, mobil iletişim sağlayıcısı olan bir abonelik gerektirir. Buna dayanarak kullanıcı mobil ağa erişebilir. UART (Evrensel Asenkron Alıcı Verici) arabirimi, paralel ve seri formatlar arasındaki verileri kodlar ve kodları çözer. Baytlarca veri alınır ve bir bit dizisi halinde iletilir. Böylece, veriler seri modda TX yoluyla mikrodenetleyiciye veya ağa bir anten olarak gönderilebilir (Isa ve Sklavos, 2017).

GSM modülü, HXSR-04 Ultrasonik mesafe sensörü, DHT11 sıcaklık ve nem sensörü, MQ5 gaz sensörü ve alev sensörünün Arduino UNO üzerindeki bağlantıları Şekil. 2'de gösterilmiştir.

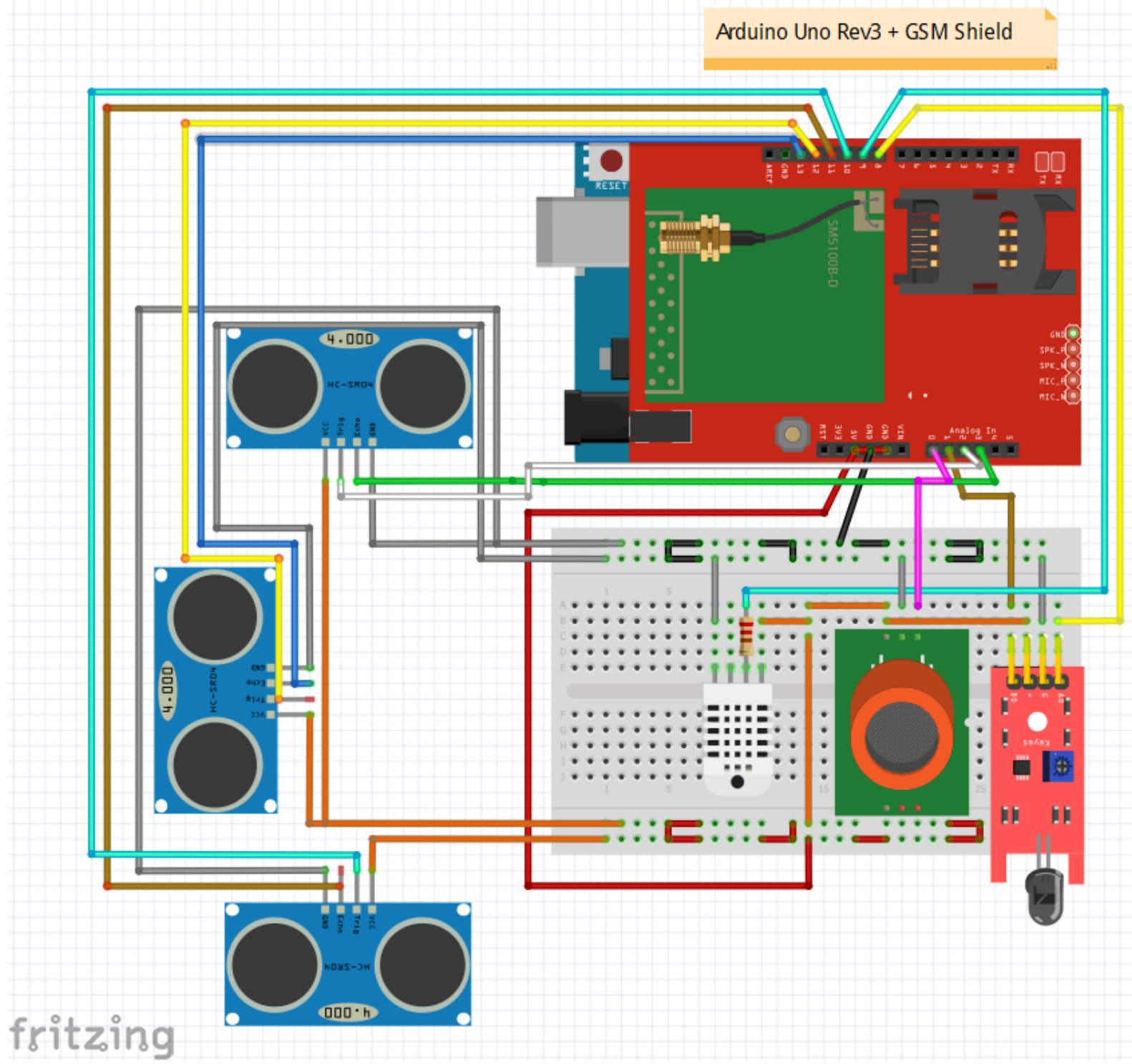

Sekil. 2 Robot devre tasarımı

Şekil. 3 'te sensörler vasıtasıyla sıcaklık ve gaz ölçümlerini yapıp GSM modülü üzerinden kullanıcılara bilgi veren robotun mekanik tasarımı gösterilmektedir.

\subsection{Yazılım}

Tasarlanan robot normal koşullarda her gün tüm evi belirli zaman aralıklarında gezmektedir. Evi gezdiği sıradaki sensörlerden alınan tüm verileri SD kartın içine kaydetmektedir. Daha sonra robot hazır vaziyette beklemeye geçmektedir. Olası bir elektrik kesintisinde ya da akıllı ev sisteminde herhangi bir arıza olması durumunda robot devreye girmekte ve tüm evi gezmektedir. Robot devreye girdiği anda SD kartın içindeki veriler YSA kullanılarak robota öğretilmektedir. Yapay zekâ metodu olarak YSA'nın MLP algoritması kullanılmıştır. YSA modeli robota öğretilirken 10 katlı çapraz doğrulama uygulanarak öğrenme için kullanılan modelin ve veri kümesinin başarısı test edilmektedir. 
MLP algoritmasıyla evin olması gereken durumlarını öğrenen robot, artık olağan dışı bir aktivite algıladığında uyarı sistemlerini devreye almaktadır. Uyarı olarak evin durumu hakkında ev sakinlerine bilgi SMS'leri atabilmektedir. Aynı zamanda kullanıcılar robot ile SMS yoluyla iletişime geçip evin durumu hakkında bilgi alabilmekte ve robota komut verebilmektedir.

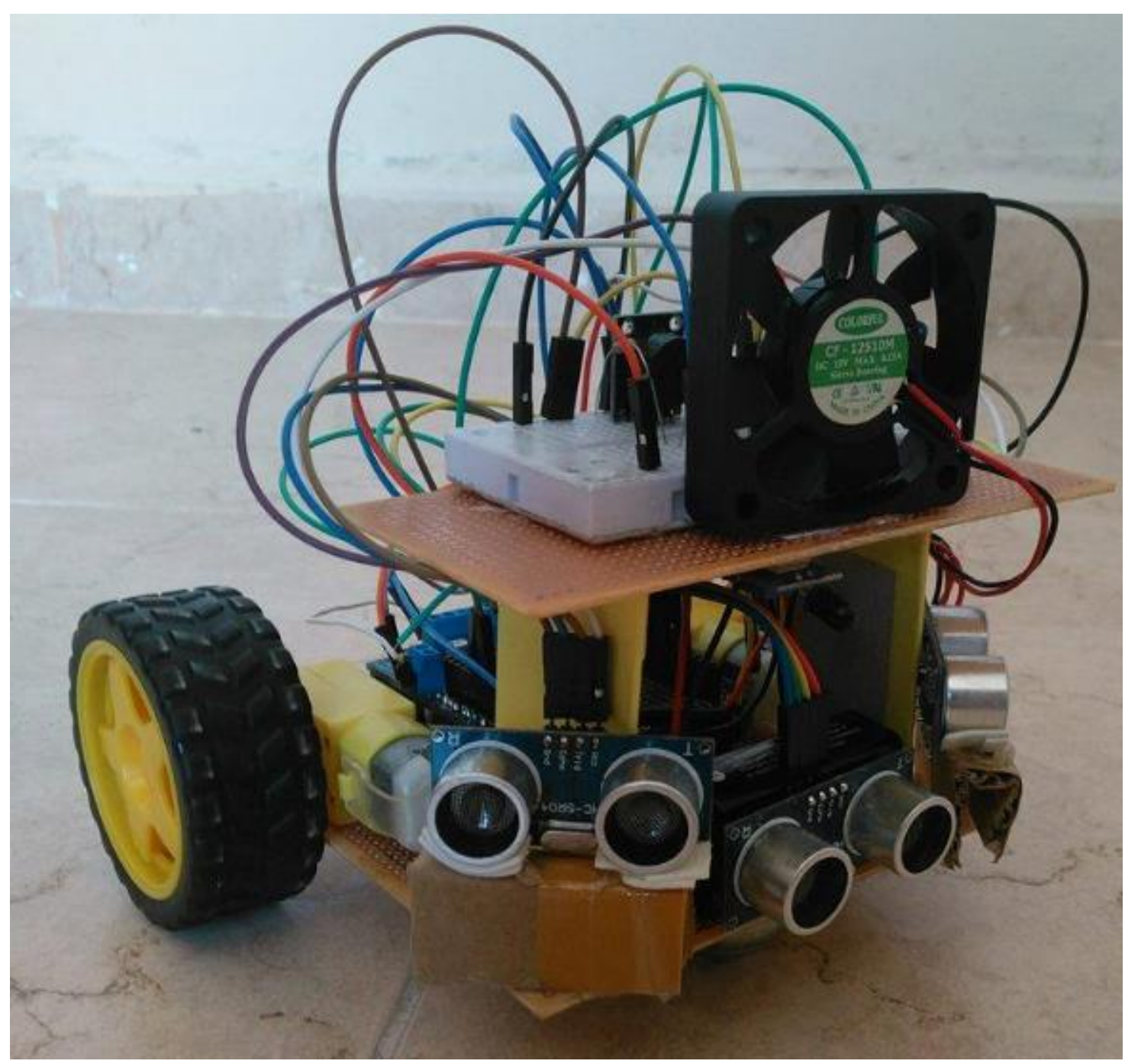

Şekil. 3 Robotun mekanik tasarımı

\subsection{Veri Kümesi ve Model}

Veri kümesi, 9 nitelikten oluşmaktadır (Tablo 1). Ön, sağ, sol ve yön sütunları robotun ev içerisinde hep aynı rotada gitmesi için gerekmektedir. Diğer parametreler (sıcaklık, gaz ve nem) evin her odasında farklı değerler olabilmektedir. Normal koşullarda robotun izlediği rotadaki bu değerler bellidir. Robot herhangi bir elektrik kesintisi ya da arıza durumunda aktif hale geldiğinde veri kümesinden öğrendiği değerler ile o anki değerleri karşılaştırıp anormal durum tespiti yapabilmektedir.

Tablo 1. Veri Kümesi Nitelikleri

\begin{tabular}{l|l}
\hline Nitelik & Açıklama \\
\hline Ön (F) & Robot ev içerisinde gezerken ön sensörden alınan mesafe değeridir $(\mathrm{cm})$. \\
\hline Sağ (R) & Robot ev içerisinde gezerken sağ sensörden alınan mesafe değeridir (cm). \\
\hline Sol (L) & Robot ev içerisinde gezerken sol sensörden alınan mesafe değeridir $(\mathrm{cm})$. \\
\hline Yön (W) & Robotun ev içerisinde gittiği yön değeridir. \\
\hline Sıcaklık (T) & Robotun ev içerisinde gezerken bulunduğu konumdaki sıcaklık değeridir $\left({ }^{0} \mathrm{C}\right)$. \\
\hline Gaz (G) & Robotun ev içerisinde gezerken bulunduğu konumdaki yanıcı gaz değeridir. \\
\hline Nem (H) & Robotun ev içerisinde gezerken bulunduğu konumdaki nem değeridir $(\%)$. \\
\hline Alev (B) & Robotun ev içerisinde gezerken bulunduğu konumdaki alev değeridir. \\
\hline Karar (D) & Robot uyarı SMS'i atsın mı atmasın mı? \\
\hline
\end{tabular}


Veri kümesinde F, R ve L değerleri robotun 3 kenarındaki ultrasonik mesafe sensöründen cm cinsinden alınan mesafe değerleri olup bu mesafe değerlerine göre W değeri hesaplanır. Hesaplanan W değeri ile robot önüne çıan engellere çarpmadan yolunu bulabilmektedir. W değeri robotun ileri (F), geri (B), sağa (R) ve sola (L) dönmesi gerektiğine karar verir.

Robot evi gezdiği sırada bulunduğu yerlerin sıcaklık (T) ve gaz değerlerini (G) kayıt etmektedir. DHT11 sıcaklık ve nem sensörü, $0-50{ }^{\circ} \mathrm{C}$ arasında $2{ }^{\circ} \mathrm{C}$ hassasiyet ile sıcaklık ve \%20-90 RH arasında $\% 5 \mathrm{RH}$ hata payı ile nemölçer. MQ5 gaz sensörü, 300 ppm ve 10.000 ppm konsanstrasyonlarda propan algılar. Ortamdaki propan gazının tehlikeli boyutlarda olduğunu algılayabilmek için sensörün algılayacağı eşik değeri 300 olarak belirlenmiştir.

Ev içerisinde herhangi bir yerde yangın varsa robot bunu üzerindeki alev sensörü ile algılar. Alev sensörü dijital çıkış verir (0-1). Alev sensörünün algıladığı değerin 0 olması alev yok, 1 olması ise alev var demektir. Veri kümesinin örnek içeriği Tablo 2'de gösterilmiştir.

Tüm veri kümesi robota YSA'nın MLP algoritması ile öğretildikten sonra robot artık ev içerisinde bulunduğu yerde olması gereken sensör değerlerini bilmektedir. Olağan dışı sensör değerleri algılarsa D değeri 1 olacak ve robot kullanıcılara uyarı SMS'i atarak herhangi bir felaket durumunun erkenden algılanmasına yardımcı olacaktır.

Yapay zekâ modeli olarak YSA’nın MLP modeli kullanılmıştır. MLP ağlarında nöronlar katmanlar şeklinde organize edilmiştir. MLP'de ilk katman girdi katmanıdır. Girdi katmanı, çözülmesi istenilen problem ilişkin bilgilerin YSA'ya alınmasını sağlar. Diğer katmanlar ise ağ içerisinde işlenen bilginin dışarıya iletildiği çıktı katmanıdır. Girdi ve çıktı katmanlarının arasında yer alan katmana ise gizli katman adı verilir. MLP ağlarında birden fazla gizli katman da bulunabilir. MLP ağlarında geri yayılım algoritması kullanılmaktadır. Geri yayılım algoritması danışmanlı öğrenme yapısına sahip ve birçok uygulamada kullanılmış yaygın bir öğrenme algoritmasıdır (Kaynar ve Taştan, 2009).

Tablo 2. Veri Kümesi Örneği

\begin{tabular}{c|c|c|c|c|c|c|c|c}
\hline $\mathbf{F}$ & $\mathbf{R}$ & $\mathbf{L}$ & W & T & G & H & B & D \\
\hline 117 & 4 & 54 & F & 24 & 50 & 68 & 0 & 0 \\
\hline 89 & 16 & 54 & F & 24 & 50 & 68 & 0 & 0 \\
\hline 104 & 18 & 52 & F & 24 & 40 & 69 & 0 & 0 \\
\hline 91 & 31 & 53 & F & 25 & 50 & 72 & 0 & 0 \\
\hline 2 & 30 & 3 & L & 25 & 55 & 71 & 0 & 0 \\
\hline 2 & 30 & 5 & L & 24 & 50 & 68 & 0 & 0 \\
\hline 2 & 30 & 5 & L & 26 & 50 & 69 & 0 & 0 \\
\hline 2 & 29 & 4 & L & 25 & 50 & 71 & 0 & 0 \\
\hline 2 & 30 & 3 & L & 24 & 55 & 71 & 0 & 0 \\
\hline 6 & 8 & 54 & R & 24 & 50 & 71 & 0 & 0 \\
\hline 2 & 2 & 53 & R & 25 & 40 & 67 & 0 \\
\hline 9 & 3 & 54 & R & 26 & 50 & 67 & 0 \\
\hline 3 & 4 & 3 & B & 24 & 50 & 70 & 0 & 0 \\
\hline 2 & 3 & 3 & B & 25 & 55 & 69 & 0 & 0 \\
\hline 3 & 4 & 3 & B & 24 & 40 & 69 & 0 & 0 \\
\hline
\end{tabular}

\section{Bulgular ve Tartışmalar}

Çalışmada kullanılan modelin temel özellikleri aşağıda listelenmiştir:

- Giriş - Çıkış nöron sayısı: 8 - 1

- $\quad$ Gizli Katman Sayısı: 50

- Aktivasyon Fonksiyonu: logistic

- Öğrenme Oranı: constant

- İterasyon Sayısı: 10.000

A ğ eğitilirken 10 katlı çapraz doğrulama uygulanmış ve ağın performansı MSE, MAE ve R ile ölçülmüştür. R değeri, hedef ve öngörülen değerler arasındaki kolerasyonu ölçmek için, MSE değeri, hataların karelerinin ortalamasını almak için, MAE değeri ise tahminlerin hedef değerlere yakınlığını ölçmek için kullanıldı (Witten ve ark., 2016). 


$$
\begin{gathered}
M S E=\frac{1}{n}\left[\sum_{i=1}^{n}\left(O_{i}-P_{i}\right)^{2}\right] \\
M A E=\frac{1}{n} \sum_{i=1}^{n}\left|O_{i}-P_{i}\right| \\
R=\sqrt{1-\frac{\sum_{i=1}^{n}\left(O_{i}-P_{i}\right)^{2}}{\sum_{i=1}^{n}\left(O_{i}-O_{m}\right)^{2}}}
\end{gathered}
$$

Burada $\mathrm{P}_{\mathrm{i}}$, öngörülen değer, $\mathrm{n}$ test için kullanılan veri nokta sayısı, $\mathrm{O}_{\mathrm{i}}$ gözlenen değer ve $\mathrm{O}_{\mathrm{m}}$ gözlemlenen değerlerin ortalamasıdır.

Elde edilen performans değerleri Tablo 3'te gösterilmiştir. En iyi sonuç 8. katta MSE için 0.1241, MAE için 0.0826 ve R için 0.9792 olarak hesaplanmıştır.

Tablo 3. Sonuçlar

\begin{tabular}{c|c|c|c}
\hline Fold \# & MSE & MAE & R \\
\hline 1 & 0.9035 & 0.7312 & 0.9126 \\
\hline 2 & 0.7547 & 0.5269 & 0.9326 \\
\hline 3 & 1.2344 & 1.0859 & 0.7907 \\
\hline 4 & 0.8129 & 0.2298 & 0.8972 \\
\hline 5 & 0.5833 & 0.3129 & 0.9621 \\
\hline 6 & 0.6732 & 0.4623 & 0.9453 \\
\hline $\mathbf{8}$ & 0.7769 & 0.4365 & 0.8816 \\
\hline 9 & $\mathbf{0 . 1 2 4 1}$ & $\mathbf{0 . 0 8 2 6}$ & 0.9792 \\
\hline Ortalama & 0.6234 & 0.5378 & 0.7833 \\
\hline
\end{tabular}

\section{Sonuçlar ve Öneriler}

Bu çalışmada, akıllı ev sisteminde herhangi bir arıza oluşması durumunda devreye girecek bir destek robotu geliştirilmiştir. Robot olası bir arıza halinde kullanıcılara evdeki durumu SMS ile haber verecek şekilde tasarlanmıştır ve R için 0.9792 başarı ile olası tehlikeleri doğru şekilde algılamıştır. Aynı zamanda kullanıcılarla SMS yolu ile iletişime geçerek herhangi bir felaket durumunda erken müdahale edilmesini sağlamıştır.

Çalışmada elde edilen sonuçlar, çalışmanın bu tip problemlerde etkin kararlar verebildiğini ve geliştirilebileceğini göstermiştir. İlerleyen süreçte geliştirilen MLP modelinin başarısını arttırmak ve yeni yöntemler denemek için çalışmalar yapılacaktır.

\section{Teșekkür}

Bu çalışma Mersin Üniversitesi Bilimsel Araştırma Projeleri Birimince 2019-1-TP2-3222 Proje Numarası ile desteklenmiştir. 


\section{Kaynakça}

Vatansever, F, \& Deniz, S. (2013). Genetik Algoritma Tabanlı PID Kontrolör Simülatörü Tasarımı. Uludağ University Journal of The Faculty of Engineering, 18(2), 7-18.

Yıldız, M, \& Yıldırım, B. F. (2018). Yapay Zekâ Ve Robotik Sistemlerin Kütüphanecilik Mesleğine Olan Etkileri. Türk Kütüphaneciliği, 32(1), 26-32.

Akkaya, G. (2007). Yapay sinir ağları ve tarım alanındaki uygulamaları. Atatürk Üniversitesi Ziraat Fakültesi Dergisi, 38(2), 195-202.

Güllü, A. (2017). Labirentlerde Yapay Zekâ Tabanlı Yön Bulma Algoritmaları Kullanan Bir Gezgin Robot Geliştirilmesi, Doktora Tezi, Trakya Üniversitesi Fen Bilimleri Enstitüsü.

Öztemel, E. (2003). Yapay sinir ağlari. Papatya Yayincilik, Istanbul.

Lins, A. P. S, \& Ludermir, T. B. (2005, November). Hybrid optimization algorithm for the definition of mlp neural network architectures and weights. In Fifth International Conference on Hybrid Intelligent Systems (HIS'05) (pp. 6-pp). IEEE.

Başçıl, M. S, Çetin, O, Er, O, \& Temurtaş, F. (2012). Olasılıksal sinir ağının (PNN) parkinson hastalığının teşhisinde kullanılması. Electronic Letters on Science\&Engineering, 8(1), 1-10.

Ersoy, H, Madran, R. O, \& Gülbahar, Y. (2011). Programlama dilleri öğretimine bir model önerisi: robot programlama. Akademik Bilişim, 11.

Asadullah, M, \& Ullah, K. (2017, April). Smart home automation system using Bluetooth technology. In 2017 International Conference on Innovations in Electrical Engineering and Computational Technologies (ICIEECT) (pp. 1-6). IEEE.

Yu, Q. S, Duan, M. Y, Zhang, T. S, Wu, H. G, \& Lu, S. K. (2014). An wireless collection and monitoring system design based on Arduino. In Advanced Materials Research (Vol. 971, pp. 1076-1080). Trans Tech Publications.

Kasbe, M. S, Deshmukh, S. L, Mujawar, T. H, Bachuwar, V. D, Deshmukh, L. P, \& Shaligram, A. D. (2015). An Electronic nose with LabVIEW using SnO2 Based Gas Sensors: Application to test freshness of the fruits. International Journal of Scientific \& Engineering Research, 6(4), 1977.

Zhou, Y, Zhou, Q, Kong, Q, \& Cai, W. (2012, April). Wireless temperature \& humidity monitor and control system. In 2012 2nd International Conference on Consumer Electronics, Communications and Networks (CECNet) (pp. 2246-2250). IEEE.

Chauhan, J. S, \& Semwal, S. (2013). Microcontroller based speed control of dc geared motor through rs-232 interface with pc. International Journal of Engineering Research and Applications (IJERA), 3(1), 778-783.

Isa, E, \& Sklavos, N. (2017). Smart Home Automation: GSM Security System Design \& Implementation. Journal of Engineering Science \& Technology Review, 10(3).

Kaynar, O, \& Taştan, S. (2009). Zaman Serisianalizinde Mlp Yapay Sinir Ağları ve Arıma Modelinin Karşılaştırılması. Erciyes Üniversitesi Iktisadi ve İdari Bilimler Fakültesi Dergisi, (33), 161-172.

Witten, I. H, Frank, E, Hall, M. A, \& Pal, C. J. (2016). Data Mining: Practical machine learning tools and techniques. Morgan Kaufmann. 